\title{
Letters
}

\section{ASCOT: a tale of two treatment regimens}

\section{Don't lose your head over ASCOT}

EDITOR-McDougall et al reviewed the evidence from ASCOT (the Anglo Scandinavian cardiac outcomes trial). ${ }^{1}$ For patients with hypertension and for the clinicians helping to manage their blood pressure this must be the best of times and the worst of times. The best of times-currently we have a wealth of clinical trials on the management of blood pressure, giving us a mass of data, statistics and information to absorb. The worst of times-whenever a new trial is published, the headlines are presented as though the paper gives the missing clue to a previously unsolvable riddle. Often the media are alerted, and unhelpful and simplistic messages are broadcast to the nation.

ASCOT merely adds to our understanding of the importance of managing blood pressure effectively. It does not cancel out the key trials of the past. In the same way ALLHAT gives an indication of the benefit of diuretics in treating hypertension. ${ }^{2}$ ASCOT does not trump ALLHAT, and the authors' assertion that diuretics will become adjunctive treatment is not supported by the evidence.

The difficulty we have with ASCOT is interpreting the absolute value of the results given that the trial itself was stopped before the primary end point reached significance. Had the trial been allowed to continue would it have shown a significant difference in the primary end point? We do not know.

We should not overlook the importance of some of the secondary end points, but equally we need to see them in context, and appreciate the absolute risk reductions and numbers needed to treat rather than the relative risk reductions that the editorial misleadingly quotes.

The editorial does not mention that the clinical guideline from the National Institute for Health and Clinical Excellence (NICE) on hypertension actually has two arms: one combining diuretic and $\beta$ blocker and the other combining diuretic and angiotensin converting enzyme (ACE) inhibitors. ${ }^{3}$ Certainly the place of $\beta$ blockers is coming under scrutiny, and clarification of their position in the algorithm would be helpful.
In the meantime it will be better if we concentrate on managing the blood pressure by using a range of agents. The current NICE algorithm of starting with a thiazide and adding in an ACE inhibitor seems well supported by the evidence from previous trials. We shouldn't lose our heads over ASCOT.

David G Phizackerley prescribing team manager Western Sussex Primary Care Trust, Chichester PO19 6FX david.phizackerley@wsx-pct.nhs.uk

Competing interests: None declared.

1 McDougall C, Brady AJB, Petrie JR. ASCOT: a tale of two treatment regimens. $B M J$ 2005;331:859-60. (15 October.) 2 The ALLHAT Officers and Coordinators for the ALLHAT Collaborative Research Group. Major outcome in high-risk hypertensive patients randomised to ACE inhibitor or calcium channel blocker vs diuretic-the ALLHAT trial. JAMA 2002;288:2981-97.

3 National Institute for Health and Clinical Excellence. Management of hypertension in primary care. Clinical guideline 18 London: NICE, 2004.

\section{Is ASCOT-BPLA being hyped-up?}

EDITOR-McDougall et al discuss whether the small absolute differences in secondary outcomes seen in the ASCOT-BPLA study were attributable to the blood pressure differences achieved. ${ }^{1}$ They use the accompanying paper to argue that this was in fact not 南 so. $^{2}$

However, the editorial that accompanies the ASCOTBPLA study severely criticises this post-hoc analysis and considers that the $2.7 \mathrm{~mm} \mathrm{Hg}$ 这 systolic gradient is sufficient to explain the cardiovascular ${ }^{\circ}$ benefit of amlodipine with or without perindopril. ${ }^{3-4}$ The authors go as far as saying, "Unfortunately, the companion article in today's Lancet, by Neil Poulter and colleagues, weakens the key message that in hypertensive patients it is the lowering of blood pressure that produces most of the benefit, and thereby opens the door for possible misinterpretation, or even misuse of post-hoc results by drug marketers." This is indeed happening and probably keeping the Association of the British Pharmaceutical Industry busy dealing with complaints.

I am puzzled why, given the evidence base, that a thiazide was not chosen as the first line drug in the "old arm" and when atenolol was chosen, why the dose was increased to $100 \mathrm{mg}$ daily. The $B N F$ has, for as long as I can remember, advised not to go above $50 \mathrm{mg}$ daily as all you do is increase side effects. How much has this "high" dose of atenolol contributed to new onset diabetes? It is not surprising therefore that the "old" arm lowered blood pressure less effectively. What happened to the third line drug, doxazosin? Was it used more often in the atenolol arm? Given its poor performance compared with thiazide in ALLHAT, this might be very important information. For an alternative view of ASCOT-BPLA, and in my opinion a more reasonable one, I would direct readers to www.pharmj.com/ pdf/spectrum/pj_20051001_ascot.pdf.

Peter D Burrill assistant director of public health Prescribing and Clinical Effectiveness, Chesterfield Primary Care Trust, Chesterfield S41 7PF peter.burrill@chesterfieldpct.nhs.uk

\section{Competing interests: None declared.}

1 McDougall C, Brady AJB, Petrie JR. ASCOT: a tale of two treatment regimens. BMJ 2005;331:859-60. (15 October.) 2 McDonald MA, Simpson SH, Ezekowitz JA, Gyenes G, Tsuyuki RT. Angiotensin receptor blockers and risk of Tsuyuki RT. Angiotensin receptor blockers and risk of
myocardial infarction: systematic review. BMJ 2005;331:

3 Staessen JA, Birkenhager WH. Evidence that new Staessen JA, Birkenhager WH. Evidence that new
antihypertensives are superior to older drugs. Lancet antihypertensives

2005;366:869-71. 4 Dahlof B, Sever PS, Poulter NR, Wedel H, Beevers GD, Caulfield M, et al. Prevention of cardiovascular events with an antihypertensive regimen of amlodipine adding perindopril as required versus atenolol adding bendroflumethazide as required, in the Anglo-Scandinavian cardia outcomes BPLA): a multicentre randomised controlled trial. Lancet 2005;366:895-906

5 The ALLHAT Officers and Coordinators for the ALLHAT Collaborative Research Group. Major outcomes in high-risk hypertensive patients randomised to $\mathrm{AC}$ inhibitor or calcium channel blocker vs diuretic-the ALI-
HAT trial. JAMA 2002;288:2981-97.

\section{Odds are that it's hype}

EDITOR-The editorial on ASCOT seems to back hype rather than evidence based medicine. ${ }^{1}$ The 2004 update of the British Hypertension Society's guideline recommends first line use of angiotensin modifying drugs in non-black people younger than 55, apparently on the basis of a study with 56 patients that looked at blood pressure response. ${ }^{2}$ The contemporaneous recommendations from the National Institute for Health and Clinical Excellence (NICE), based on a big review that looked at tens of thousands of subjects in studies examining the clinical outcomes of death, stroke, and myocardial infarction, concluded that thiazides are the most cost effective first line treatment for most people, ${ }^{3}$ with either angiotensin converting enzyme (ACE) inhibitors or $\beta$ blockers added in, at the next step.

Should ASCOT change the NICE conclusion? In the previous issue of the $B M /$ an article by Freemantle exhorted caution about reading too much into a study that did not reach significance for the primary 
outcome. ${ }^{4}$ ASCOT did not reach significance for the primary outcome. McDougall et al back "newer" drugs in the initial management of blood pressure, ${ }^{1}$ but ASCOT compared treatment based on amlodipine (a calcium channel blocker) with treatment based on atenolol (a $\beta$ blocker). Amlodipine is not a new drug and is out of patent. Perindopril, a "newer" drug in the ACE inhibitor class, was used as add-in treatment to amlodipine in ASCOT and is still in patent and actively promoted: Could this be related to current hype?

MacMahon et al, exploring the role of perindopril in the PROGRESS study, said: "Let's set aside arguments about elusive special drug effects and focus on the issue of prime importance. To adapt the well known words of a recent US president: 'It's the blood pressure, stupid.5 The odds are that it is the blood pressure, and thiazides still remain cheap and effective as the first treatment for most people.

Martin G Duerden general practitioner

Meddygfa Gyffin, Conwy LL32 8LT

martin@theduerdens.co.uk

\section{Competing interests: None declared.}

1 McDougall C, Brady AJB, Petrie JR. ASCOT: a tale of two treatment regimens. BMJ 2005;331:859-60. (15 October.) Dickerson JC, Hingorani AD, Ashby MJ, Palmer CR, and Brown MJ. Optimisation of antihypertensive treatment by Brown MJ. Optimisation of antihypertensive treatment by
crossover rotation of four major classes. Lancet 1999:353: crossover

3 National Institute for Health and Clinical Excellence. Management of hypertension in primary care. Clinical guideline 18.

4 Freemantle N. How well does the evidence on pioglitazone back up researchers' claims for a reduction in

lar events? BMJ 2005;331:836-8. (8 October.)

Machars less distraction. BMI 2004:329:970-1.

\section{Is ASCOT all it's cracked up to be?}

EDITOR-Am I alone in thinking the ASCOT study fails to answer the question it was set to answer, and moreover raises some more? ${ }^{1}$ McDougall et al seem sure that it has clearly shown that the new combination of angiotensin converting enzyme (ACE) inhibitor and calcium antagonist is beneficial compared with a $\beta$ blocker and thiazide. ${ }^{2}$

Firstly, did the inclusion criteria bias the study against $\beta$ blockers? Patients with peripheral vascular disease and microalbuminuria were included whereas patients with biochemical abnormalities were not. This looks as if it might favour ACE inhibitors over $\beta$ blockers.

Secondly, the study showed no significant difference between the two groups with regard to the primary end points, nor any significant difference for secondary end points once blood pressure differences between the two groups were allowed for. ${ }^{3}$ McDougall et al say that all the benefits seen in the patients allocated to the amlodipineperindopril regimen were unlikely to be attributable solely to more effective lowering of systolic blood pressure. ${ }^{2}$ Does that mean they agree that it is not significant, or not?

The ASCOT study has shown that the lower the reduction in blood pressure, the better (at least with regard to cardiovascular morbidity and mortality). ASCOT clearly shows the large difference in diabetes in the two groups: roughly $5.9 \%$ prevalence in the amlodipine group and $8.3 \%$ in the atenolol group. How much of the difference between the two figures is "prevention" and how much is "cause"?

As a GP I was also interested to see that $78 \%$ of patients required two or more agents by the end of the study, with $8 \%$ taking four or more. Only $15 \%$ of patients were taking a single agent by the end of the five years. Only $53 \%$ of the patients in the study reached their target blood pressure, and among patients with non-insulin dependent diabetes this figure was just $32 \%$.

Does this single study outweigh such meta-analyses as that by Pahor et al, who clearly concluded that calcium antagonists could not be recommended as first line agents? ${ }^{3}$ By matching the treatment with the individual (including the discussion of risk), we can ensure that more than half of our patients reach target and a less than one in five suffer adverse effects of their treatment.

James A Cave general practitioner partner Downland Practice, Chieveley, Newbury RG20 8UY ectopicmailbox-bmj1@yahoo.co.uk

Competing interests: JAC is a dispensing doctor and shareholder of Downland Services, a pharmacy. If he changes to prescribing newer more expensive drugs he may lose out from his primary care trust's prescribing incentive scheme if he overspends the practice budget. Conversely, use of more expensive drugs may attract more income from dispensing for himself and the pharmacy.

1 Dahlof B, Sever PS, Poulter NR, Wedel H, Beevers GD, Caulfield $\mathrm{M}$ et a Prevention of ardiovascular events with Caunthe an antihypertensive regimen of amlodipine adding perincopril as required, in the Anglo-Scandinavian azide as required, in the Anglo-Scandinavian cardiac outcomes trial-blood pressure lowering arm (ASCOTBPLA): a multice

McDougall C, Brady AJB, Petrie JR ASCOT: a tale of two treougall C, Brady AJB, Petrie JR. ASCOT: a tale of two Peactorer.) Poulter NR, Wedel H, Dahlof B, Sever PS, Beevers GD, Caulfield M, et al. Role of blood pressure and othe ariables in the differential cardiovascular event rate in the Anglo-Scandinavian cardiac outcome rial-blood pressu

Pahor M Psaty BM, Alderman MH, Applegate WB, William, Psaty BM, Alderman MH, Applegate WB, Williamson JD, Cavazzini C, et al. Health outcomes associced with calciun antagonists conpared wh oher

randomised controlled trials. Lancet $2000 \cdot 356 \cdot 1949-54$.

\section{Trastuzumab for early breast cancer raises important issues}

EDITOR-The government's recent announcement that all early stage breast cancer patients are to be tested for HER2 overexpression with a view to receiving trastuzumab (Herceptin) will no doubt be a great relief to both patients and oncologists.

However, this raises several important issues.

Firstly, the government may be setting a dangerous precedent in effectively promoting off-licence indications for a pharmaceutical (what oncologist, presented with a patient who could benefit from this drug, will not use his or her clinical discretion to prescribe it off-label?).

Secondly, it is pre-empting the evaluations of both the European Agency for the
Evaluation of Medicinal Products (EMEA, the licensing agency) and the National Institute for Health and Clinical Excellence (NICE), the body set up to advise the government on value for money in the NHS.

But most importantly, it highlights the terrible decisions necessary in any health system: the oncologist sees a sick patient and knows there is a treatment available that may help them. However, the director of public health in the primary care trust has limited funds (which in many cases are already overspent) and a duty to get the best possible health care for the entire population with those funds. Trastuzumab costs in the region of $£ 20000$ per patient per year. A typical primary care trust (170 000 population) may have 23 eligible patients, ${ }^{2}$ thus costing an additional $£ 460000$. Without the drug, on average two of the patients may die each year. ${ }^{3}$ With it, one of them may survive. Therefore the stark decision faced by the trust is whether it can withdraw $£ 460000$ from other services at a "cost" of less than one life elsewhere. To this there is no easy answer.

Edward C F Wilson research associate

Health Economics Group, School of Medicine, Health Policy and Practice, University of East Anglia, Norwich NR4 7TJ

ed.wilson@uea.ac.uk

Competing interests: None declared.

1 Mayor S. Women with early breast cancer to be tested for trastuzumab treatment. BMJ 2005;331:864. (15 October.) 2 National Horizon Scanning Centre. Trastuzumab as adjuvant therapy for early stage breast cancer. Birmingham: University of Birmingham, 2005.

3 Fritz P, Cabrera CM, Dippon J, Gerteis A, Simon W, Aulitzky WE, et al. c-erbB2 and topoisomerase I $\alpha$ protein expression independently predict poor survival in primary human breast cancer: a retrospective study. Breast Cancer Res 2005; 7:R374-84.

4 Piccart-Gebhart MJ. First results of the HERA trial. ASCO scientific session, Orlando, Florida, May 2005.

\section{Left handedness and breast cancer}

\section{Correlation is spurious}

EDITOR-Ramadhani et al present the results of the prospective study analysing the contribution of innate hand preference, among several other factors, to the development of breast cancer. ${ }^{1}$ They conclude that innate left handedness and the development of premenopausal breast cancer are associated. The mechanism by which this occurs has not been established, although the authors speculate that the origin of the association may lie in intrauterine exposure to steroid hormones. Rather than being used as evidence for causality, the authors should consider whether the link between both handedness and the incidence of breast cancer and a common third variable (exposure to sex hormones in the womb) indicates that the apparent association is nothing more than a spurious correlation. ${ }^{2}$ Until this has been addressed and controlled for, their conclusion that left handedness is related to increased risk of breast cancer is not valid.

Adrian J Bloor specialist registrar in haematology University College Hospital, London NW1 2BU drbloor@tiscali.co.uk 


\section{Competing interests: None declared.}

1 Ramadhani MK, Elias SG, van Noord PAH, Grobbee DE, Peeters PHM, Uiterwaal CSPM. Innate left handedness an risk of breast cancer: case-cohort study. BMJ 2005;331

Stigler SM. Correlation and causation: a comment. Perspect Biol Med 2005:48:S88-S94.

\section{Should left handed premenopausal women be screened?}

EDITOR-Ramadhani et al do not tell us in their article what implications for the management of breast cancer (if any) their results will have. ${ }^{1}$ The incidence of left handedness in the general population is about $11.5 \%(10-11 \%$ of women and about $13 \%$ of men). ${ }^{2}$ The incidence for breast cancer is $1: 8$ over a lifetime for a women, 1:2212 at the age of 30, 1:235 at the age of 40, 1:54 at the age of 50, and 1:23 at the age of $60 .{ }^{3}$ Screening for breast cancer is currently available in the United Kingdom for women older than 50 by means of mammography, an investigation not routinely performed under the age of 35. Given the small numbers of women actually affected by the results of the study reported by Ramadhani et al, inventing a new screening tool for this "population at risk" seems unnecessary.

The study does further not mention any impact of family history on the results. Have the authors checked for hereditary breast cancer (BRCA1 and BRCA2 gene carriers) and familial breast cancer?

Bettina Lieske specialist registrar in vascular surgery Oxford OX3 9DU

Bettina_Lieske@yahoo.co.uk

\section{Competing interests: None declared.}

1 Ramadhani MK, Elias SG, van Noord PAH, Grobbee DE, Peeters PHM, Uiterwaal CSPM. Innate left handedness and risk of breast cancer: case-cohort study. BMJ 2005;331 882-3. (15 October.)

2 McManus C. Right hand, left hand. London: Phoenix, Orion Books, 2003

3 Feuer EJ, Wun LM. DECAN: probability of developing or dying of cancer. Version 4.0. Bethesda MD: National Cancer Institute, 1999.

\section{Authors' reply}

EDITOR-We did not first find an association and only then start speculating about mechanisms. As clearly indicated in our paper, first came a hypothesis about influences in the womb, including exposure to steroids, and breast cancer risk. ${ }^{1}$ Like the group that proposed this hypothesis, ${ }^{2}$ we used handedness as a putative marker for such early life influences. As we did find an association which is obviously not directly causal, we subsequently speculated that the original hypothesis might underlie it.

Speculations are different from conclusions. We speculated that our findings may support other researchers' hypotheses. Our conclusion is restricted to the observation that we did, cautious in our view, and without any reference to causality. The validity of our conclusion that left handedness is related to increased risk of breast cancer does not depend on speculations about putative mechanisms, but on whether the observation is correct, unbiased. We will consider our findings spurious only if we are shown that flaws in our study design, conduct, or analysis have led us to report an association that actually does not exist.

Lieske asks about the implications of the association between left handedness and breast cancer for the management of the disease. We avoided any reference to practical implications because we believe that our findings currently do not allow for such thinking.

Our study was intended as an aetiological study aiming at another investigation of causes of breast cancer. We used handedness as a possible marker of such causes. Other studies on the relation between hand preference and breast cancer have not all been consistent

Therefore, this research is in the stage of confirmation rather than application.

Our analysis was focused exclusively on hand preference as the determinant and breast cancer as the outcome, while accounting for other breast cancer risk factors as possible confounders. Our purpose was particularly not to assess the (additional) predictive value of hand preference in conjunction with other breast cancer predictors. ${ }^{2}$ When thinking about selective screening for breast cancer, many predictors need to be taken into account for individual women, with an as yet unknown contribution of hand preference. The relation with left handedness applied to premenopausal breast cancer. The absolute risk for such cancer is low, and although we did no formal analysis, we anticipate no role for handedness as a predictor of that risk to justify its use as a breast cancer risk screening tool.

We accounted for family history (in mother or sister) in the analysis as mentioned in the table legend of our paper, and this did not influence our findings. We did not consider hereditary breast cancer, which accounts for only a small proportion of all cases of breast cancer. Specifically, we did not consider it a confounder in the association that we studied.

Cuno S P M Uiterwaal assistant professor of clinical epidemiology

c.s.p.m.uiterwaal@umcutrecht.n

Diederick E Grobbee professor of clinical

epidemiology

Julius Centre for Health Sciences and Primary

Care, University Medical Centre Utrecht,

PO Box 85500, 3508 GA Utrecht, Netherlands

Competing interests: None declared.

1 Trichopoulos D. Hypothesis: does breast-cancer originate in utero? Lancet 1990;335:939-40.

2 Titus-Ernstoff L, Newcomb PA, Egan KM, Baron JA Greenberg ER, Trichopoulos D et al. Left-handedness in relation to breast cancer risk in postmenopausal women Epidemiology 2000;11:181-4.

\section{Scientific evidence was ignored in CAM and the NHS}

EDITOR-We would like to correct an error in Thompson and Feder's description of the methodology of our systematic review of UK cost effectiveness studies of complementary and alternative medicine (CAM). ${ }^{12}$ We did not search for randomised studies. We included all prospective, controlled studies of any CAM modality carried out in the UK. All five happened to be randomised.

That there were only five such studies restricted to spinal manipulation (four studies) and acupuncture (one) and that only three of them make useful comparisons with usual care, underlines the paucity of such data in the UK. A further study on acupuncture for back pain has a similar result: a small effect size of questionable clinical significance in a trial design without patient blinding or sham control and a favourable estimate of cost per quality adjusted life year (QALY). ${ }^{3}$ Such studies may simply be estimating the cost effectiveness of placebo treatment. Pragmatic designs do not, as is often argued, resemble real life treatments any more than gold standard randomised clinical trials; they are just methodologically weaker.

Counting Cochrane reviews is a simplistic method of assessing the current evidence base in CAM and seems to contradict Thompson and Feder's call for each modality to be assessed on its own merits. It makes more sense to look at the most recent and comprehensive systematic reviews for each modality. Sixteen systematic reviews of spinal manipulation for various indications have been published since 2000, 13 of them concluding that its effectiveness remains unproved. Acupuncture has enjoyed a stronger evidence base, but an updated systematic review to be published shortly seems to show that effect sizes are becoming smaller as clinical trials use more rigorous designs and larger sample sizes. ${ }^{4}$ The results of large scale clinical trials of acupuncture carried out in Germany will also be published shortly and are expected to indicate that the effectiveness of real and sham treatment are similar. ${ }^{4}$

Despite this and the paucity of cost effectiveness data, Thompson and Feder advocate getting on with the incorporation of CAM into NHS guidelines and appear nervous in case that task is left to the National Institute for Health and Clinical Excellence (NICE). This debate is clearly more to do with politics than with scientific medicine.

Peter H Canter research fellow

peter.canter@pms.ac.uk

Edzard Ernst director

Complementary Medicine, Peninsula Medical

School, Exeter EX2 4NT

Competing interests: None declared.

1 Thompson T, Feder G. Complementary therapies and the NHS. BMJ 2005;331:856-7. (15 October.)

2 Canter PH, Thompson Coon J, Ernst E. Cost effectiveness of complementary treatments in the United Kingdom: sysof complementary treatments in the United Kingdo

3 Thomas KJ, MacPherson H, Ratcliffe J, Thorpe L, Brazier J Campbell M, et al. Longer term clinical and economic benefits of offering acupuncture care to patients with chronic low back pain. Healh Technology Assessment 2005;

4 Linde K. Acupuncture for chronic pain: an update of systematic reviews. Twelfth annual symposium on complementary health care, Exeter, September 2005. 


\section{Disappointing article, not disappointing biotech}

EDITOR-Joppi et al's critique and not biotech itself is disappointing. ${ }^{1}$

The authors classified most of the biotech drugs (24/61) as "copycat or me too products"-pejorative terms intended to cast prejudicial doubt on a drug's value. I am familiar with one of the drugs on the copycat list, teriparatide (rhPTH1-34, Forteo, Eli Lilly), a treatment for osteoporosis. I helped with its development. Teriparatide was the first and remains the only drug in its class approved for osteoporosis. It was the first bone anabolic agent ever widely approved in Europe. Many experts have deemed teriparatide an important addition to the treatment options for osteoporosis. If an obviously pioneering innovation such as teriparatide may be classified by Joppi et al as a copycat, one must question all drugs on the "copycat" list.

Four of the 15 innovative drugs classified by Joppi et al were for orphan diseases, which by definition affect very small populations with high unmet need. They criticise use of placebo controlled studies with "soft" end points for orphan drugs. A placebo controlled study is almost always the preferred study design for diseases without established treatments. By choosing the term "soft," the authors prejudice the reader by implying that the studied endpoints were invalid or irrelevant. Regulatory authorities do not accept just any end point as a basis for approval; the primary end point must be relevant to the disease and the purported drug action. With an orphan disease, it is in everyone's interests to find an effective medicine as quickly as possible. A placebo controlled study with a primary end point that most quickly determines a relevant drug effect must be chosen. In other words, the four orphan drugs identified in this paper were likely to have been developed appropriately.

Fredric J Cohen president

Pharma Growth Strategies LLC, 3331 Street Road, Suite 140, Bensalem, PA 19020, USA

fred@pharmagrowth.com

Competing interests: None declared.

1 Joppi R, Bertele' V, Garattini S. Disappointing biotech. BMJ 2005;331:895-7. (15 October.)

\section{Proposed guidelines for severe imported malaria in children need more evidence}

EDITOR-The proposed UK guidelines for severe childhood malaria are an excellent attempt to improve the care of children with severe imported malaria, ${ }^{1}$ but we are concerned about the following.

Firstly, the use of parenteral antibiotics. The "high risk group" would include less than $5 \%$ of children with imported malaria. ${ }^{2}$ Children with these features in the United Kingdom are likely to have bacterial septic shock or meningitis, even with a history of foreign travel. Furthermore, it is impossible to differentiate between septic shock or meningitis and severe malaria. ${ }^{34}$ The management algorithm should, therefore, recommend giving empirical broad spectrum antibiotics to children with high risk criteria until bacterial infection can be excluded.

Secondly, transfusion. The authors propose that children with haemoglobin counts $<100 \mathrm{~g} / \mathrm{l}$ should be managed in a high dependency unit and be transfused. In east London 65/211 (31\%) presented with haemoglobin counts of 50-100 g/l, and none developed complications despite being managed conservatively. ${ }^{2}$ A Cochrane review found no difference in mortality between initial and expectant transfusion in children with malarial anaemia, but more adverse events with initial transfusion. ${ }^{5}$ Recommendations for transfusion should be reconsidered, given the current UK move to decrease transfusions.

Thirdly, oral quinine. The authors recommend that children should "never" receive oral quinine. However, according to the $B N F$, oral quinine remains effective, is cheap, and is well tolerated by children. In east London, only $1 / 192$ children $(0.5 \%)$ receiving quinine relapsed. ${ }^{2}$ Treatment with mefloquine should be avoided because of concerns about resistance. Further studies are necessary before recommending newer antimalarials.

Fourthly, non-falciparum malaria. The proposed guidelines only apply to Plasmodium falciparum malaria and may lead to confusion about non-falciparum malaria, which is unlikely to be severe. The suggested treatment for "uncomplicated malaria" would also be inappropriate and more costly than currently recommended chloroquine. A 12 month study of imported malaria through the British Paediatric Surveillance Unit (http://bpsu.inopsu.com) will start later this year. We aim to collect comprehensive information to support future recommendations for the management of imported malaria.

Shamez Ladhani research fellow, paediatric infectious diseases

DrShamez@aol.com

Delane Shingadia senior lecturer, paediatric infectious diseases

Academic Centre for Child Health, Royal London Hospital, London El 2AX

F Andrew I Riordan consultant, paediatric infectious diseases and immunology Royal Liverpool Children's Hospital (Alder Hey), Eaton Road, Liverpool L12 2AP

\section{Competing interests: None declared.}

1 Maitland K, Nadel S, Pollard AJ, Williams TN, Newton CR, Levin M. Management of severe malaria in children: proposed guidelines for the United Kingdom. $B M J$ 2005;331:337-43.

2 Ladhani S, El Bashir H, Patel VS, Shingadia D. Childhood malaria in East London. Pediatr Infect Dis J 2003;22:814-9. 3 Berkley JA, Mwangi I, Mellington F, Mwarumba S, Marsh K. Cerebral malaria versus bacterial meningitis in children K. Cerebral malaria versus bacterial meningitis in child
with impaired consciousness. QJ Med 1999;92:151-7.
4 Berkley J, Mwarumba S, Bramham K, Lowe B, Marsh K. Bacteraemia complicating severe malaria in children. Trans R Soc Trop Med Hyg 1999;93:283-6.

5 Meremikwu M, Smith HJ. Blood transfusion for treating malarial anaemia. In: Cochrane Library. Issue 2. Oxford: Update Software, 2003.

\section{Speed networking works for postgraduate research}

EdiToR-We were intrigued to read Ridd and Shaw's recent communication on the use of a modified form of "speed dating" to improve their collaborative academic outlook in Bristol. ${ }^{1}$ We are pleased to report a refinement of this method and its application to the identification of research and education projects, and supervisors, for students undertaking the MSc in primary health care at King's College London.

At the first meeting of our MSc cohort $(n=8)$ and senior researchers and educators (their potential project supervisors, $\mathrm{n}=9$ ), we used a modification of the Ridd and Shaw methodology, extending the contact time between student and supervisor to about five minutes (recognising the conversational needs of our qualitative researchers) and supplemented the process with a printed handout, reminding students of supervisors' research and education interests and providing contact details. Using this method we were able to introduce all students to all the supervisors in under an hour, during which the energy and enthusiasm in the room were palpable.

All involved agreed that this was an effective and enjoyable way of making preliminary contact, and the mean student satisfaction score, on a Likert scale with a maximum score of 10 , was 7.75 . We recommend the continued use and development of this approach as an excellent means of breaking the ice at events where academic collaboration of various kinds is being sought.

Roger H Jones Wolfson professor of general practice King's College London, Department of General Practice and Primary Care, London SE11 6SP roger.jones@kcl.ac.uk

On behalf of the MSc Faculty and students, Department of General Practice and Primary Care, King's College, London.

Competing interests: None declared.

1 Ridd MJ, Shaw ARG. "Speed networking" may be one way forward. BMJ 2005;331:695 (24 September.).

\section{bmj.com}

Letters appearing here are an edited selection of rapid responses originally posted on bmi.com

We ask for all letters to the editor to be submitted as rapid responses via bmj.com

For advice see: bmj.com/rapidresponses 